\title{
Recognition of Short-Range Photogrammetry and Its Applications for Recording and Maintaining Cultural and Natural Heritage
}

\author{
Ali Khaki \\ Architecture, Technical and Vocational University, Tehran, Iran \\ Email: Dr.alikhaki@yahoo.com
}

Published online: 30 June 2020

To cite this article: Ali Khaki (2020). Recognition of short-range photogrammetry and its applications for recording and maintaining cultural and natural heritage. Journal of Engineering Science, 16(1), 1-18, https://doi.org/10.21315/jes2020.16.1.1.

To link to this article: https://doi.org/10.21315/jes2020.16.1.1

\begin{abstract}
Documenting, recording and maintaining information related to valuable monuments and cultural heritage is one of the steps in recognising and protecting historical works and buildings. Archaeologists and the experts of historical works by threedimensional modelling of real texture can work on virtual images of the desired building all over the world without the need of spending time and cost to travel to that place and perform any historical, materialogical and technological study. This research by investigating and introducing the application of new methods in cultural heritage registration seeks to investigate the application of photogrammetric science in the preservation and restoration of historical works and buildings. In short-range photogrammetry, using a series of images of an object, a precise model of its geometry can be achieved. This technique is typically used for documentations with complex geometric properties or a large number of architectural spaces and components such as mogharnas in mosques and other complex decorations. In short-range photogrammetric method, the coordinates of the boundary points of the parts are deduced and by comparing the geometrical parameters of the boundaries and finding similarities between the boundaries, the similar parts are graphically connected to each other to form an initial three-dimensional model for reconstructing the discovered objects.
\end{abstract}

Keywords: short-range photogrammetry, cultural heritage, monuments, ancient works, three-dimensional model

\section{INTRODUCTION}

Nowadays, three-dimensional modelling and displaying the surrounding space with measurement capability in the models has highly been considered. The threedimensional models prepared with real texture can have various applications in various fields such as documenting and recording ancient works and buildings, ${ }^{1}$ 
preparing three-dimensional virtual models, ${ }^{2}$ computer games, ${ }^{3}$ navigation, ${ }^{4}$ intelligent systems with the capability of understanding the environment and decision making, ${ }^{5}$ and so on. Photogrammetry is a French word and it means measuring recorded light. It has become a new method in today's world that has been very effective and assisting in the field of restoring ancient works. To date, the conceptions and documentations of ancient works, that is the first and very important step in the science of restoration have been done by manual methods and consequently these achievements were not without error. Today, with the use of short-range photogrammetry for restoration and with regard to the relative justification parameters of the position of the object location, this possibility has been provided for the accurate documentation of ancient works, monuments displacement survey and pathogenesis. ${ }^{6,7}$

In a standard scientific project, documentation and data collection has a special position performed by experts having knowledge in all sciences. ${ }^{8}$ In fact, documenting is among the basic and first steps in any research that without passing through this step the desired results cannot be achieved and the project cannot be completed successfully. Documenting the historical heritage or recording the status quo in the archaeological conceptions is no exception from this issue and the greater the effort is made in this respect and the updated technologies are used, the results of the researches will be far more accurate and will have higher value. ${ }^{9-12}$

In this respect, the use of computer and digital technologies in the field of cultural heritage registration has grown significantly. The rapid advancement in the production of types of computer systems and various software we are witnessing everyday have greatly influenced the practices of mapping and documenting cultural heritage (as shown in Figure 1). New methods that record historical data much more accurately and quickly than traditional methods are rapidly developing. ${ }^{13}$

Short-range photogrammetry can be named as an inexpensive and accurate measurement method for preparing the map of the status quo of small industrial, archaeological structures, facades of buildings and so on. Short-range photogrammetry is the gateway for the achievement of this discipline to all other disciplines of engineering (industry, medicine, cultural heritage, accidents, criminal issues, etc.). ${ }^{14}$ 


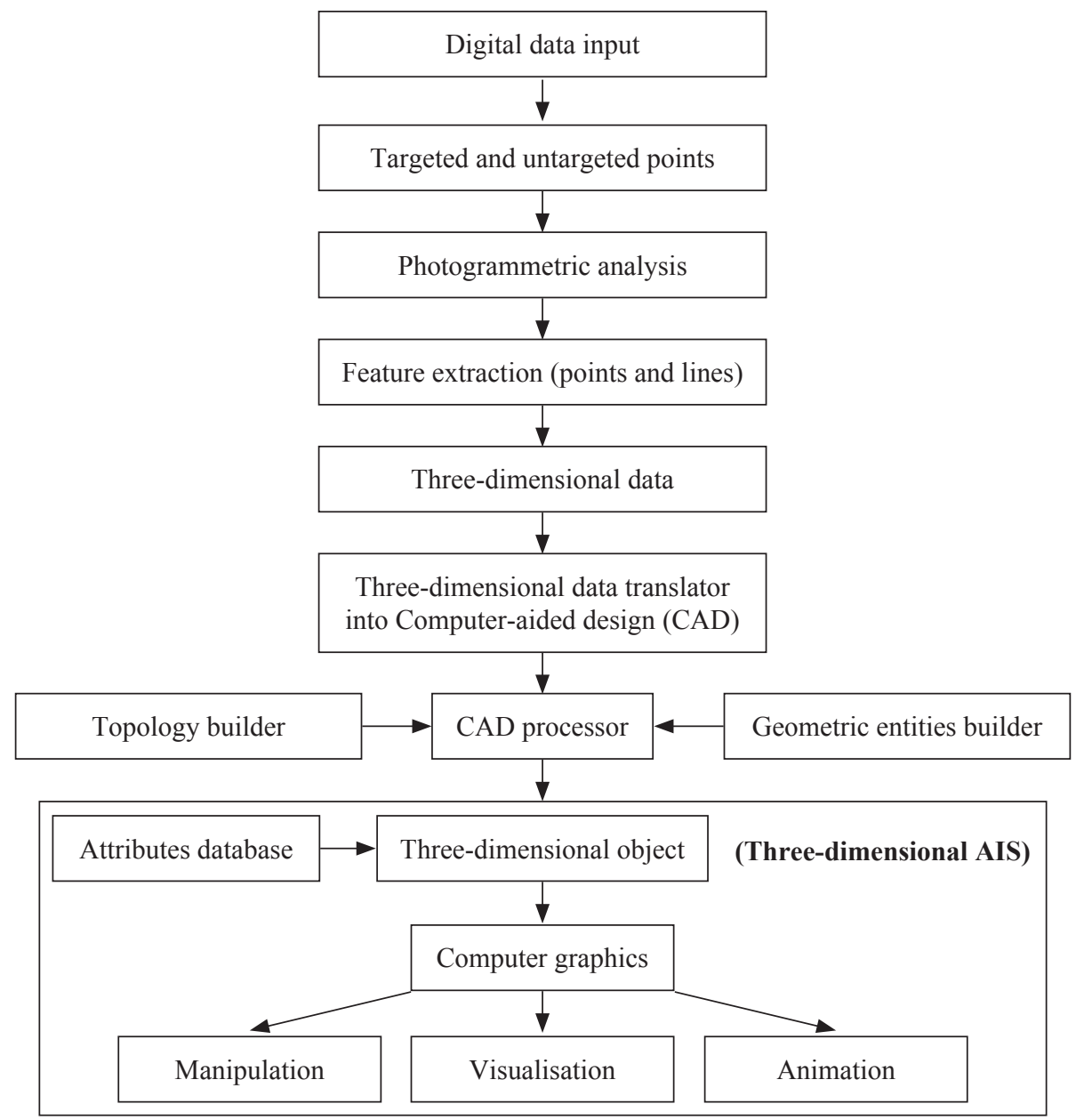

Figure 1: Brief investigation of proposed archaeological information system (AIS). ${ }^{15}$

\subsection{Physical Documentation}

Physical documentation means the complete and accurate conception of a monument or historical site with respect to all the complexities and details existing in the plan, volumes, decorations, site and so on. In fact, the purpose of documentation is to prepare very accurate maps of the monument or historical site, usually prepared at 1:10 to 1:50 scale. Various methods such as mapping, classic mapping, short-range photogrammetry, laser scanners and remote sensing are used to do this work, that each of these tools and methods has its own precision. The main factors determining the choice of each of these tools and methods (i.e. object size: monument or historical site) and the ratio of its complexities are shown in Figure 2. 


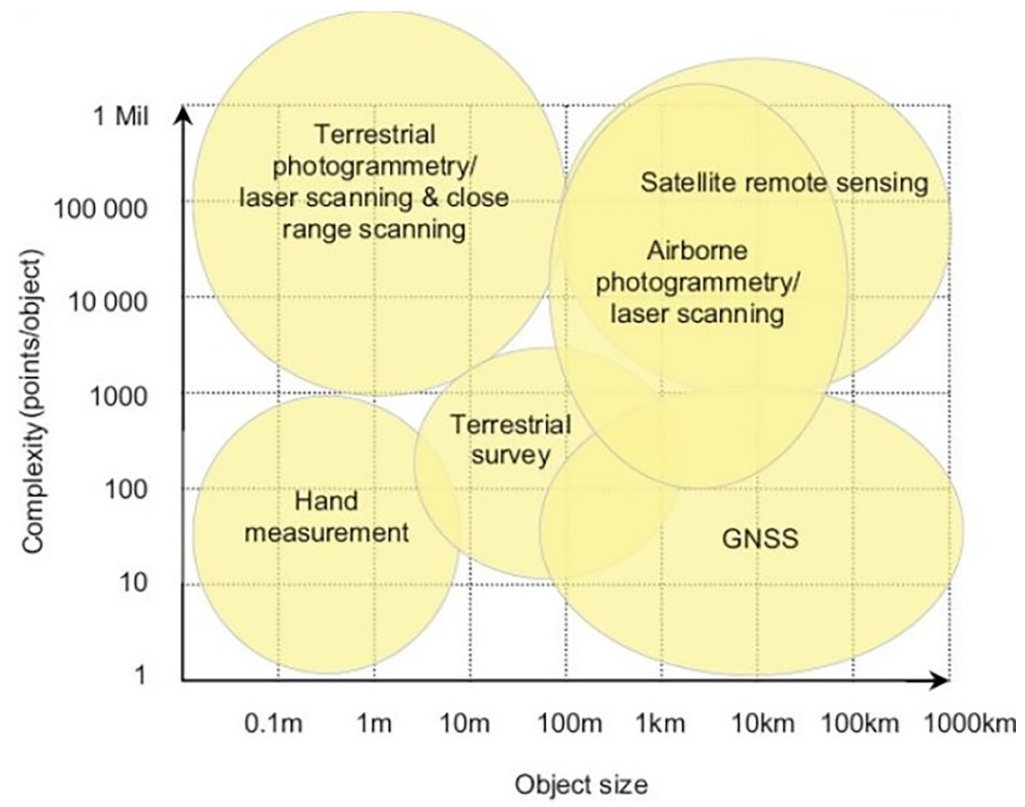

Figure 2: Relationship between the size of an object and its complexities for selecting the conception tool.

In these methods, it is possible to perform accurate investigations on the monument or historical site by creating three-dimensional models. Nowadays, with the improvements made, it can be said that the older and manual methods are less used and the newer methods such as photogrammetric and laser scanner techiques have more applicability due to the speed and also precision.

\subsection{Background of Short-Range Photogrammetry Application in Historical Heritage Documentation}

With a look at the history of photogrammetric science, we will observe that the first photogrammetric activities in the field of mapping and in particular the mapping of monuments come back to the $1867 \mathrm{AD}$, and concurrent with the emergence of the photography technique. After World War II, the use of photogrammetry in recording ancient and historical works of various countries increased dramatically until the World Association of Photogrammetry and Remote Sensing in 1948 AD, allocated one of its seven groups that is Group 5 to the short-range photogrammetry, which has presented numerous meetings and publications so far. After this event since $1964 \mathrm{AD}$, in many countries, systematic photogrammetric activities were formed to map cultural heritage. ${ }^{16}$ 

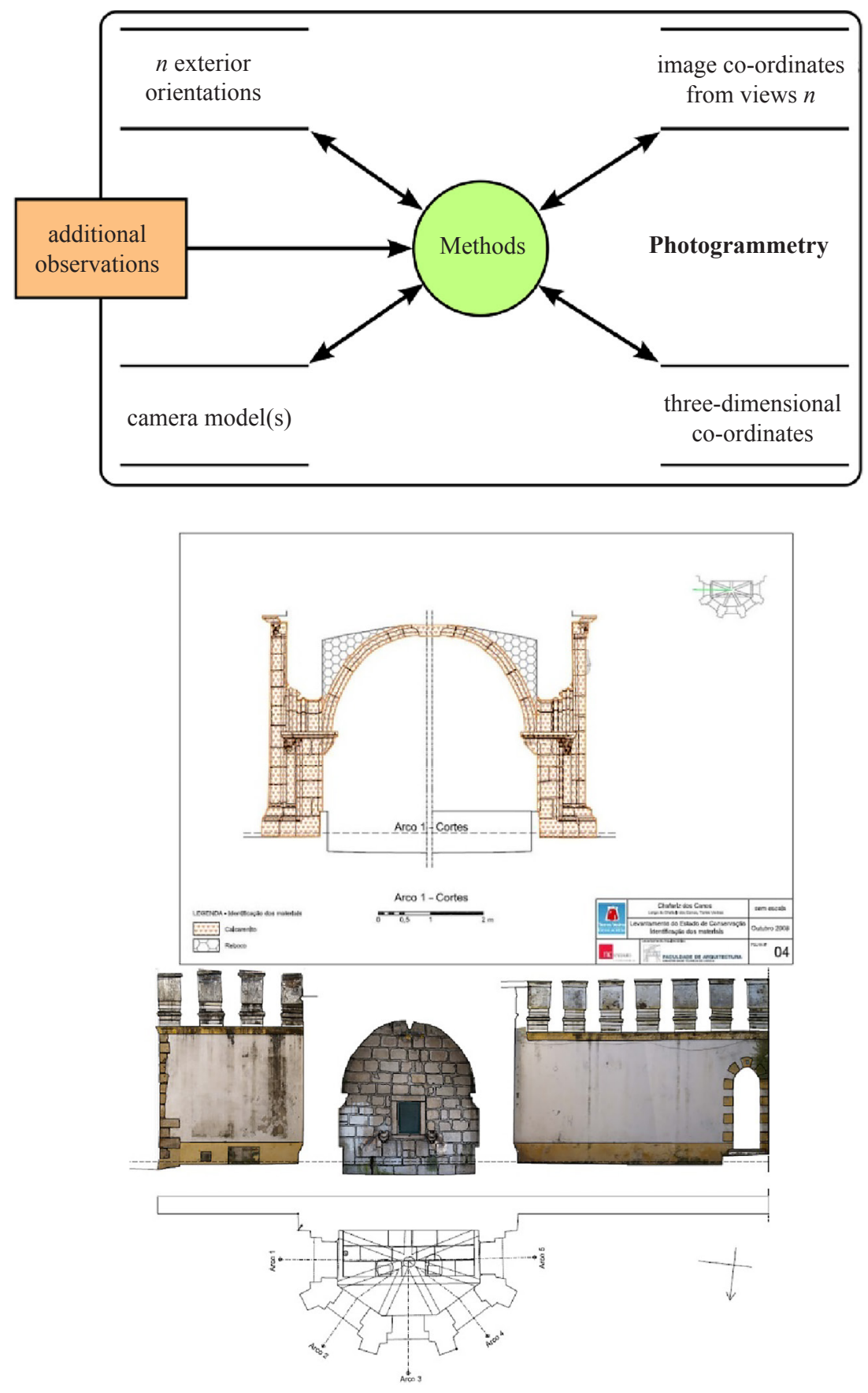

Figure 3: Monument photogrammetry related to 19th century building located in Lisbon, Portugal. 
The United Nations Educational, Scientific and Cultural Organisation (UNESCO) has jointly proposed photogrammetric methods to the member states and has taken extensive measures to expand this technique and has required countries to register their cultural heritage. The International Council on Monuments and Sites (ICOMOS) is also the inventor of the first meeting on the use of photogrammetry in the registration of cultural heritage and the International Committee of Photogrametery and Architecture (CIPA) was also founded in 1970 with the suggestions of this association.

\subsection{Photogrammetry}

In the last decade new technologies have been created for documenting through using advanced tool that have made interdisciplinary activities in the field of architecture and archeology possible. ${ }^{17}$ Short-range photogrammetry is considered as an efficient and fast method in conception that can be used in recording and modelling the architectural and decorative buildings.

In general, short-range photogrammetry is one of the three-dimensional measurement methods and among the most important advantage of it, the lower cost, high speed and reduction of human errors can be mentioned. ${ }^{18}$ As a result, this method will be a proper alternative for two-dimensional and three-imensional conceptions. The short-range photogrammetric method is more suitable for small objects or limited-scale buildings. In this method, by a series of photographs of the desired subject an accurate geometric model of it can be obtained. This technique is usually used for documentations with complex geometric properties or a large number of spaces, including walls, paving or sidewalks, debris and architectural components. ${ }^{19}$

Photogrammetry is stated as the science, technique and art of determining the position and measurement of the shape of an object using digital or analog images analysis. ${ }^{20}$ In this definition very explicitly many unknowns about photogrammetry are answered. We deal with an image in photogrammetry (as shown in Figures 4 and 5). ${ }^{21}$ In other words, we perform measurements or more simply conception using the analysis of images taken from the desired object. ${ }^{22}$ So with any type of image, whether spatial, aerial or short-range, the measurement and conception can be done in various states. With the same approach, the photogrammetry in a classification is divided into three parts: spatial, aerial and terrestrial (short-range) photogrammetry. In spatial photogrammetry, we deal with satellite images and this method is used to prepare map from large regions such as a city or a province. ${ }^{23}$ In aerial photogrammetry, since the images are taken by aircraft, the flight altitude is reduced, and this method can be used to prepare a 
map from regions to the extent of a city or part of it. But in the latter state, if, in one type of classification, camera to object distance is less than $300 \mathrm{~m}$; the stages of preparing the map is located among terrestrial photogrammetry or short-range photogrammetry. ${ }^{24}$

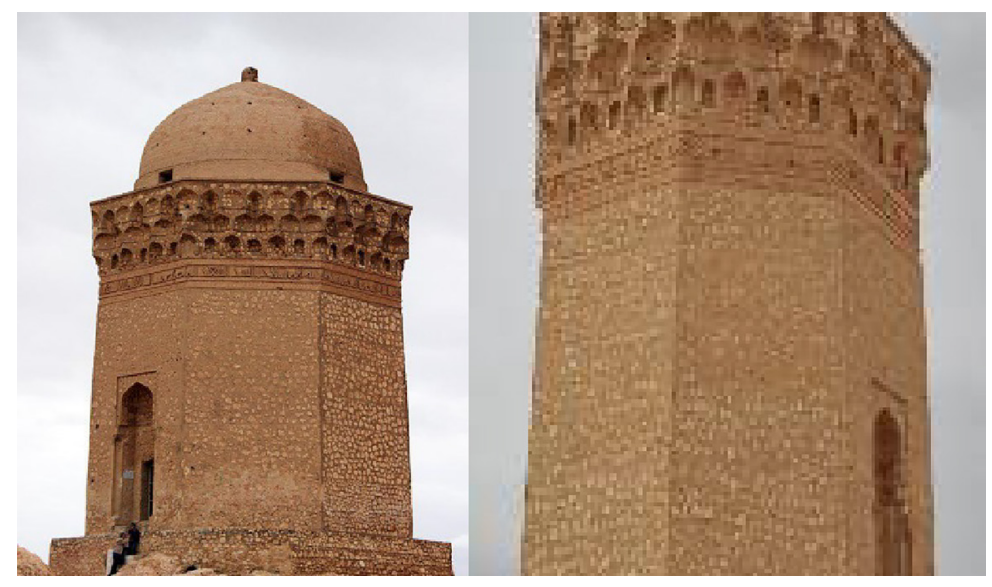

Figure 4: Image of Supreme Dome Tower in Abarkuh County, Yazd, Iran taken by shortrange photogrammetric principles.
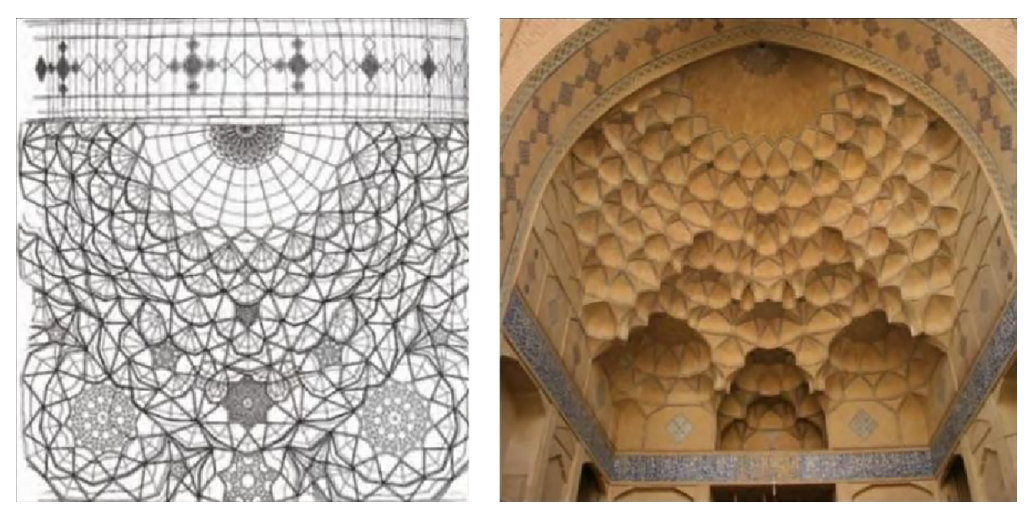

Figure 5: Image of Mogharnas of the main porch of Isfahan Jame Mosque taken by short-range photogrammetric principles. Image courtesy of Cultural Heritage Organisation (2011). 


\section{THREE-DIMENSIONAL MODELLING METHODS}

There are various methods of documenting monuments that are used depending on the project conditions. The methods are briefly introduced in the following subsection.

\subsection{Three-Dimensional Laser Scanner}

Three-dimensional scanning by laser scanner is one of the important and practical methods. Terrestrial laser scanners are widely used for the conception of monuments and historical sites. The accuracy of this method is very high and its data conception rate is relatively high, although the process of cloud processing of points obtained from laser scanners and preparing a clean and accurate threedimensional model requires spending the considerable time of laboratory work compared to the field conception time. Therefore, the high cost and the difficulty of data processing are other features that limit the use of this system. Also in working with terrestrial laser scanner technology, geometrical information of the surface of objects is obtained and either the texture information of the desired surface is not recorded or if the images of texture are taken, compared with short-range photogrammetry it has low separation power and quality. ${ }^{25,26}$

\subsection{Photogrammetry}

Another method of documenting is photogrammetry. The science and technology of obtaining geometrical and interpretive information from a photo is called photogrammetry, which is divided into three branches of spatial (photography camera installed on satellite), aerial (photography camera installed on aircraft) and short-range photogrammetry (photography camera at a distance about less than 300 $\mathrm{m}$ from the object). ${ }^{27}$ The short-range photogrammetric method is more suitable for small objects or limited-scale buildings. In this method, with a series of photographs from the desired subject an accurate geometric model can be achieved from it. This technique is commonly used for documentations with complex geometric properties or a large number of spaces, including walls, paving or sidewalks, debris and architectural components. ${ }^{19}$ Among the advantages of photogrammetric method are: it is low cost, it has speed in doing the stages of field conception and subsequent processing, proper accuracy of geometrically and radiometrically obtained models, having variety of final geometric and demonstration models, having colour and capable of assessing the changes with low cost. ${ }^{25}$ 
Short-range documenting methods, in respect of the complexity of the work can be classified into two general categories: complex (professional) photogrammetric methods and simple (unprofessional) photogrammetric methods. In complex photogrammetric methods, equipments are usually used that may be unavailable to everyone or because of their high cost, the possibility of preparing them is not provided to everyone. Conversely, equipments used in simple (unprofessional) photogrammetric methods are usually available to everyone and because of their low cost compared to professional photogrammetric equipments, preparing them is possible to everyone, among which usual non-metric and inexpensive cameras, simple photogrammetry and demonstration modelling software, simple mapping equipments (such as meter and ruler, etc.), common in the market, can be mentioned..$^{28}$

In documenting archaeological buildings, method selected are usually depending on the purpose of the modelling process. For prominent record, inscription or decorations purposes, where photographs with full information needed, photogrammetry will provide more complete and accurate information. Other than that, in case of preparing a three-dimensional model that have numerous levels, such as the whole of a building, three-dimensional laser scanner is more efficient. ${ }^{29}$

Virtual reality, augmented reality and three-dimensional geographic information systems are other modern technologies in three-dimensional visualisation and modeled resources management which can be utilised in documenting, depending on their features..$^{25,30}$

\subsection{Image-Based Three-Dimensional Modelling Process}

Image-based three-dimensional modelling (IBM), is the technique of producing a three-dimensional model of an object by the aid of its two-dimensional images. ${ }^{7}$ In general, the IBM process is based on several successive steps: ${ }^{25}$

1. Designing the network of geometry

2. Three-dimensional dimensions (sparse point cloud and dense point cloud)

3. Structuring and modelling (triangles and grid generation and surface creation)

4. Texture production and visual representation 


\subsection{Short-Range Photogrammetric Imaging}

Short-range photogrammetry is a branch of the science of photogrammetry that measures, conceptualises and models objects and sites using the analysis of close-up taken images. This means that three-dimensional modelling is only obtained by using images taken from the object. ${ }^{31}$ Considering that the recent advancements in the field of digital cameras production and the removal of analog cameras, the photogrammetric science has also had significant advances, especially in recent years. ${ }^{32}$ If we want to have a look at the past software used in the short-range photogrammetry, we will witness their evolution process from Target-based software such as Australis to semi-automatic software such as Photomodeler and finally Target-free automatic software such as PhotoScan. With the technological advancement of manufacturing digital cameras and their improved imaging quality, software has also been upgraded and expanded from manual state to automatic state. It should of course be mentioned that each of these software and methods has its own applications, but what created a tremendous evolution in the field of documenting the works was the introduction of automatic images processing algorithms and software that in addition to high speed and low cost compared to other methods, the result of work has a very high quality. In addition to the above points, using non-metric cameras instead of expensive metric cameras has made this technique to be more prevalent more than ever and the number of its users increased.

The principles of short-range photogrammetry are, in fact, the creation of a mathematical relationship between the coordinate system of at least two photographs with common coverage and the three-dimensional coordinate system of the space of object (as shown in Figure 6). After the establishment of mathematical relationship, three-dimensional coordinates $(\mathrm{X}, \mathrm{Y}, \mathrm{Z})$ of the points of the object that are located in the common part of two images can be calculated, that the object or building can be modeled by having the three-dimensional coordinates. ${ }^{33,34}$

To establish relationship between the image space and the object space using mathematical models: co-page condition, four co-linear condition, or DLT5 equations can be performed, but the most common of them are co-linear condition equations (Equation 1). The meaning of co-linear condition is that an arbitrary point such as $A$ is located on the object space with the centre point of the PC1 image and the point image in the image $a 1$ is on one line (as shown in Figure 3). Overlapping these three points on a line ensures that the geometrical position of the photos coordinate system relative to the object coordinate system is exactly similar to the shooting moment, which is the main condition for the model to become three-dimensional. ${ }^{33,35}$ 

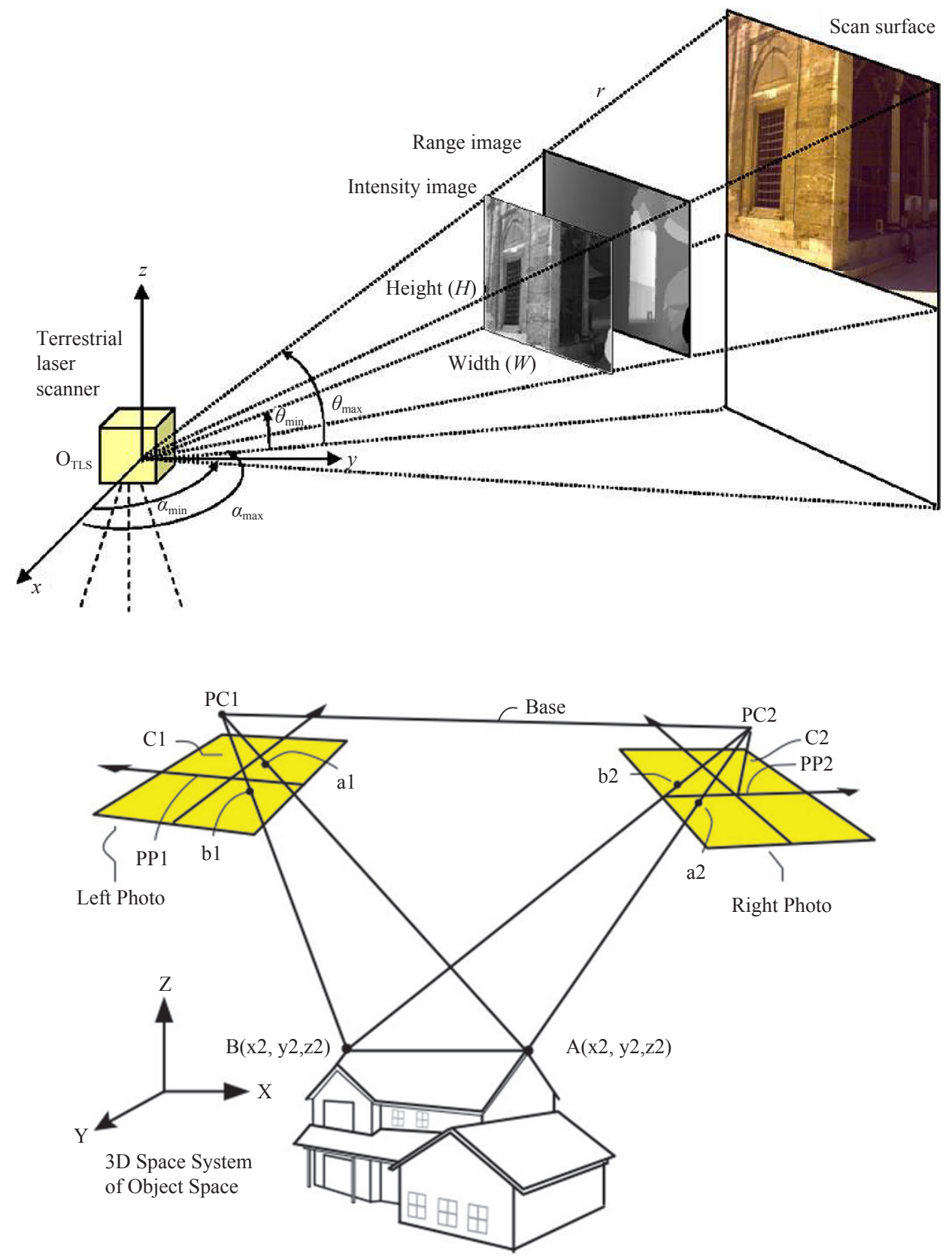

Figure 6: Principles of short-range photogrammetry. 


$$
\begin{aligned}
& x_{a}=x_{p}-f\left[\frac{r_{11}\left(X_{A}-X_{0}\right)+r_{12}\left(Y_{A}-Y_{0}\right)+r_{13}\left(Z_{A}-Z_{0}\right)}{r_{31}\left(X_{A}-X_{0}\right)+r_{32}\left(Y_{A}-Y_{0}\right)+r_{33}\left(Z_{A}-Z_{0}\right)}\right] \\
& y_{a}=y_{p}-f\left[\frac{r_{21}\left(X_{A}-X_{0}\right)+r_{22}\left(Y_{A}-Y_{0}\right)+r_{23}\left(Z_{A}-Z_{0}\right)}{r_{31}\left(X_{A}-X_{0}\right)+r_{32}\left(Y_{A}-Y_{0}\right)+r_{33}\left(Z_{A}-Z_{0}\right)}\right]
\end{aligned}
$$

In which:

$y_{a}$ and $x_{a}$ : photographic coordinates of point $a$

$y_{p}$ and $x_{p}$ : actual photo centre coordinates in the photo coordinate system

$Z_{A}, Y_{A}$ and $X_{A}$ : Point $A$ coordinates in the object coordinate system

$Z_{0}, Y_{0}$ and $X_{0}$ : PC image centre coordinates in object coordinate system

$f$ : shooting camera focal distance (equal to $\mathrm{C}$ )

$r_{i j}$ : three-dimensional period of matrix elements.

Having calculated the unknown parameters of this equation for the common known points between the two object space and photographic coordinate systems (control points), by locating the photographic coordinates of each point in the equation, its three-dimensional coordinate in the object space will be calculated.

\subsection{Short-Range Photogrammetric Imaging Position in Documenting}

Documenting is the basis and foundation of any type of research and study in various scientific fields. The higher the ratio of quality and accuracy of data at the time of documenting, the more valuable the research result will be. ${ }^{36}$ Documenting historical works, buildings and sites has not been an exception from this point, and archaeologists and restorers of the historical works have always sought to use the world's latest technologies to improve the quality of this issue. ${ }^{37-39}$ Since excavated sites or monuments usually do not have completely regular geometric shapes and have been partially destroyed over time, they have specific complexities that this point has complicated the documentation operations of them. With regard to these cases the use of an efficient and cost-effective method that can illustrate these complexities with the highest quality has always been a concern for those who are activating in this field. ${ }^{40,41}$

The new generation of short-range photogrammetry algorithms and software has to some extent removed this problem and even causing the people who do not professionally follow the science of mapping and photogrammetry and do not have specialty education in this respect can also perform documenting operations in the best way with the lowest cost and with the highest speed. 
This point should be noted that as much as technology advancement facilitated documenting by short-range method, still the lack of an engineering and metric view reduces modelling accuracy and ultimately leads to uncertainty towards this advanced technique.

\subsection{The Major Difference between Short-Range and Aerial Photogrammetry}

The main difference between short-range and aerial photogrammetry is in the imaging state that makes aerial photogrammetry algorithms are unable to be used for short-range either. In aerial imaging using manned or unmanned aircrafts, it is attempted that the taken images to be near-vertical and to have the lowest rotations in three axes. In addition, the distance between the image centres is largely equal with each other. These assumptions make the algorithms used to process aerial images a little simpler and the operation of converting the image to map is done more easily. But there are no such assumptions in short-range photogrammetry. If you have considered in short-range imaging, from various angles and in a "convergent" way, it will make the angle of the images not to be vertical to the object and the distance of the images is centred and different from each other. For this reason, aerial photogrammetry algorithms can no longer be used. The same cases change the photogrammetric algorithms slightly and thus creating a branch called short-range photogrammetry. Overall, the similarities are the usage of photo, general processing procedure and using the same fundamentals; while the differences are in dimensions, distance and workspace, and applications.

\section{CONCLUSION}

In this article, while stating an introduction regarding the science of photogrammetry, some of its applications in documenting cultural heritage are mentioned. Since in the photogrammetric technique, without direct contact with the body and only by taking several images from it, a three-dimensional model or vertical images can be prepared, damaging the works while documenting can be prevented, that this issue in turn is important. Regarding the high speed and quality of this method, as well as its low costs compared to other methods such as laser scanner and on the other hand the low budget allocated to cultural heritage documenting, it can be known as a proper alternative for conventional expensive and low precision methods. 
Today, short-range photogrammetry has been based on non-metric camera. Widely available to consumers, these cameras are increasingly being used in various applications in the field of short-range photogrammetry because of being inexpensive and low maintenance cost. Projects such as documenting historic places, simulating the architecture of buildings, modelling industrial parts and so on are cases in which non-metric cameras can be used.

Among the advantages of photogrammetry in building restoration pathology (in research units) are the speed in doing the stages of field conception and processing, appropriate accuracy of geometrically and radiometrically obtained models, variety of demonstration and final geometric models (such as, linear map and similar two-dimensional models, restored photo, OrthoPhoto, various threedimensional models as texture, the comparison models of situation at various times), low human resources to perform all stages (perhaps only one person), the possibility of repeating each project again, and updating the information and the similarity of the image processing environment, and the geometric and radiometric corrections with the drawings environment can be mentioned. In fact, it can be stated in this way that due to the great advancements in archeology both in the fields of excavation and restoration and conservation and maintenance of discovered objects and works, the use of other sciences proposed in the field of engineering along with various, applied, very accurate and fast software to register and record three-dimensional models very accurately, will significantly help the advancement of this science.

\section{REFERENCES}

1. Li-Chee-Ming, J. \& Armenakis, C. (2010). Fusion of optical and terrestrial laser scanner data. Paper presented at the 2010 Canadian Geomatics Conference and Symposium of Commission I, ISPRS Convergence in Geomatics-Shaping Canada's Competitive Landscape. Calgary, Alberta, Canada, 15-18 June.

2. Shimamura, J., Takemura, H., Yokoya, N. \& Yamazawa, K. (2000). Construction and presentation of a virtual environment using panoramic stereo images of a real scene and computer graphics models. Proceedings 15 th international conference on pattern recognition (ICPR-2000), vol. 4. Barcelona: Institute of Electrical and Electronics (IEEE), 463-467, https://doi.org/10.1109/ICPR.2000.902958.

3. Lippman, A. (1980). Movie-maps: An application of the optical videodisc to computer graphics. Comput. Graph. (ACM), 14(3), 32-42, https://doi.org/10.1145/965105.807465. 
4. Chen, S. E. (1995). Quicktime VR: An image-based approach to virtual environment navigation. SIGGRAPH '95: Proceedings of the 22nd annual conference on computer graphics and interactive techniques. New York: Association for Computing Machinery (ACM), 29-38, https://doi.org/10.1145/218380.218395.

5. Lin, T. T., Hsiung, Y. K., Hong, G. L., Chang, H. K. \& Lu, F. M. (2008). Development of a virtual reality GIS using stereo vision. Comput. Electron. Agric., 63(1), 38-48, https://doi.org/10.1016/j.compag.2008.01.017.

6. Ahmon, J. (2004). The application of short range 3D laser scanning for archaeological replica production: The Egyptian tomb of Seti I. The Photogrammetric Record, 19(106), 111-127, https://doi.org/10.1111/ j.1477-9730.2004.00034.x.

7. Alsadik, B. S. A. (2014). Guided close range photogrammetry for 3D modelling of cultural heritage sites. PhD diss. University of Twente.

8. Stanco, F., Battiato, S. \& Gallo, G. (eds.). (2011). Digital imaging for cultural heritage preservation: Analysis, restoration, and reconstruction of ancient artworks. Boca Raton, FL: CRC Press.

9. Beraldin, J. A., Picard, M., El-Hakim, S., Godin, G., Borgeat, L., Blais, F. et al. (2005). Virtual reconstruction of heritage sites: Opportunities and challenges created by 3D technologies. Paper presented at the International Workshop on Recording, Modeling and Visualization of Cultural Heritage. Monte Verita, Ascona, Switzerland, 22-27 May.

10. Timothy, D. J. (2011). Cultural heritage and tourism: An introduction, vol. 4. Bristol, UK: Channel View Publications.

11. Zomrashidi, H. \& Habibabad, A.S. (2016). Architectural decorations in the holy courts and tombstones of Imamzadegan, based on Islamic patterns. Quarterly Journal of Iranian Islamic City Studies, 24, 5-20.

12. Zomorshidi, H. \& Sadeghi, H. A. (2018). Brick and art of brickwork since ancient times to now. Quarterly Journal of Iranian Islamic City Studies, 33, 5-18.

13. Yilmaz, H. M., Yakar, M., Gulec, S. A. \& Dulgerler, O. N. (2007). Importance of digital close-range photogrammetry in documentation of cultural heritage. J. Cult. Herit., 8(4), 428-433, https://doi.org/10.1016/ j.culher.2007.07.004.

14. Böhler, W. \& Marbs, A. (2004). 3D scanning and photogrammetry for heritage recording: A comparison. Proceedings of the 12th International Conference on Geoinformatics. Gävle, Sweden: Gävle University Press, 291-298. 
15. Sajjadi, S. Y. (2017). Proposed algorithm for modelling archeological works and cultural heritage using short range digital photogrammetry. Journal of Geospatial Information Technology, 5(4), 1-21, https://doi. org/10.29252/jgit.5.4.1.

16. Blake, J. (2000). On defining the cultural heritage. Int. Comp. Law Q., 49(1), 61-85, https://doi.org/10.1017/S002058930006396X.

17. Sadeghi, A. H., MahdiNejad, J., Azemati, H. \& Matracchi, P. (2019). Using neurology sciences to investigate the color component and its effect on promoting the sense of spirituality in the interior space of the Vakil Mosque of Shiraz (using quantitative electroencephalography wave recording). J. Relig. Health, (Forthcoming), https://doi.org/10.1007/ s10943-019-00937-0.

18. Weizhong, R., Xinjian, K. \& Haomei, L. (2004). Application of digital close-range photogrammetry in deformation measurement of model test. Chin. J. Rock Mech. Eng., 23(3), 436-440.

19. Alitajer, S. \& Azad, S. A. (2013). Investigating the position of geomatic engineering in the applications of cultural-archaeological and architectural heritage. Iranian Archaeological Researches, 3(5), 169-195.

20. Drap, P., Sgrenzaroli, M., Canciani, M., Cannata, G. \& Seinturier, J. (2003). Laser scanning and close range photogrammetry: Towards a single measuring tool dedicated to architecture and archaeology. Proceedings of the XIXth international symposium of the International Committee for Architectural Photogrammetry (CIPA) 2003, New perspectives to save cultural heritage. Antalya, Turkey: CIPA, 1-6.

21. Jiang, R., Jáuregui, D. V. \& White, K. R. (2008). Close-range photogrammetry applications in bridge measurement: Literature review. Measurement, 41(8), 823-834, https://doi.org/10.1016/j. measurement.2007.12.005.

22. Tokmakidis, K. \& Scarlatos, D. (2002). Mapping excavations and archaeological sites using close range photos. International Archives of Photogrammetry Remote Sensing and Spatial Information Sciences, 34(5), 459-462.

23. Scaioni, M., Feng, T., Lu, P., Qiao, G., Tong, X., Li, R. et al. (2015). Close-range photogrammetric techniques for deformation measurement: Applications to landslides. In Modern technologies for landslide monitoring and prediction. Berlin: Springer, 13-41, https://doi.org/10 .1007/978-3-662-45931-7_2.

24. Haegler, S., Müller, P. \& Van Gool, L. (2009). Procedural modelling for digital cultural heritage. EURASIP J. Image. Vide., 2009, 852392, https://doi.org/10.1155/2009/852392. 
25. Maleki, N. A., Tasdighi, S. \& Androodi, E. (2018). Documenting monuments decorations using short range photogrammetry: Modelling the Mogharnas of north side of Masoudieh building. Paper presented at the Second National Conference on Documentation of Natural and Cultural Heritage. Shahid Rajaee University, Tehran.

26. Emami, H., Saadatseresht, M., Safari, A. (2016). Combining terrestrial laser scanning and short-range photogrammetry data by matrix mapping method to produce three-dimensional model with real texture. Journal of Mapping and Spatial Information Engineering, 7(2), 71-86.

27. Roghani, S., Hossein, M. and Naghdi, K. (2014). Modelling of monuments using short range photogrammetry and investigating threedimensional model capabilities in transferring qualitative characteristics: Case study; The Davazdah Imam Mausoleum at Yazd. Paper presented at the National Conference on Application of Advanced Spatial Analysis Models (Remote Sensing and GIS) in Land Preparation. Islamic Azad University, Yazd, Iran.

28. Miri, M. \& Warshosaz, M. (2006). Investigating the position of geomatic engineering in cultural heritage applications. Paper presented at the Conference on Geomatics. Tehran.

29. Yari, M. \& Feiz, Z. (2015). The necessity and methods of using new technologies in documenting archaeological excavations. Paper presented at the Second National Conference on Iranian Archaeology. Mashhad, Iran.

30. Abad, A. S. H., Nejad, J. M. \& Azemati, H. (2018). Review and assessment of influential components on creating and promoting the "sense of spirituality" in the architecture of the mosques. Journal of Sustainable Architecture and Urban Design, 6(1), 61-78.

31. Ducher, G. (1987). Photogrammetry: The largest operational application of remote sensing. Photogrammetria, 41(2), 72-82, https://doi. org/10.1016/0031-8663(87)90054-8.

32. Lerma, J. L., Navarro, S., Cabrelles, M. \& Villaverde, V. (2010). Terrestrial laser scanning and close range photogrammetry for 3D archaeological documentation: The upper Palaeolithic cave of Parpalló as a case study. J.Archaeol.Sci.,37(3), 499-507,https://doi.org/10.1016/j.jas.2009.10.011.

33. Salmani, M. \& Naghdi, K. (2014). Modelling monuments using short range photogrammetry and investigating three-dimensional model capabilities in transferring qualitative properties, case study: The Davazdah Imam Mausoleum at Yazd. Paper presented at the National Conference on Advanced Spatial Analysis Models Application (Remote Sensing and GIS) in Land Preparation. Yazd, Iran. 
34. Luhmann, T., Robson, S., Kyle, S. \& Harley, I. (2011). Close range photogrammetry: Principles, techniques and applications. Dunbeath, UK: Whittles Publishing.

35. Luhmann, T., Robson, S., Kyle, S. \& Boehm, J. (2013). Close range photogrammetry and $3 D$ imaging. Berlin: Walter De Gruyter Inc, https://doi.org/10.1515/9783110302783.

36. Tweed, C. \& Sutherland, M. (2007). Built cultural heritage and sustainable urban development. Landscape Urban Plan., 83(1), 62-69, https://doi.org/10.1016/j.landurbplan.2007.05.008.

37. Vecco, M. (2010). A definition of cultural heritage: From the tangible to the intangible. J. Cult. Herit., 11(3), 321-324, https://doi.org/10.1016/j. culher.2010.01.006.

38. Nejad, J. M. \& Abad, A. S. H. (2016). Expressions of Islamic ideas and foundations in the noble Iranian-Islamic architecture (case study: Khan School in Shiraz). J. Fundam. Appl. Sci., 8(3), 1115-1131, https://doi.org/10.4314/jfas.v8i3.25.

39. Nejad, J. M., Zarghami, E. \& Abad, A. S. H. (2016). A study on the concepts and themes of color and light in the exquisite Islamic architecture. J. Fundam. Appl. Sci., 8(3), 1077-1096, https://doi.org/10.4314/jfas. v8i3.23.

40. Neumüller, M., Reichinger, A., Rist, F. \& Kern, C. (2014). 3D printing for cultural heritage: Preservation, accessibility, research and education. In $3 D$ research challenges in cultural heritage. Berlin: Springer, 119-134, https://doi.org/10.1007/978-3-662-44630-0_9.

41. Portalés, C., Lerma, J. L. \& Pérez, C. (2009). Photogrammetry and augmented reality for cultural heritage applications. Photogramm. Rec., 24(128), 316-331, https://doi.org/10.1111/j.1477-9730.2009.00549.x. 